\title{
Effects of Epichloë endophyte on antioxidant enzymes activities, photosynthesis and growth of three ecotypes of Elymus dahuricus
}

\author{
Yuping ZHANG, Yanfei ZHOU, Xingxu ZHANG, Tingyu DUAN, Zhibiao NAN (凶) \\ State Key Laboratory of Grassland Agro-Ecosystem/College of Pastoral Agricultural Science and Technology, Lanzhou University, \\ Lanzhou 730000, China
}

\begin{abstract}
Fungal endophytes of some cultivated grasses can increase plant performance and competitive abilities, especially under stress. Far less is known about the influence of Epichloë infections in wild populations of wild grasses. In this study, plants of three Elymus dahuricus ecotypes (WLS, QY and WTS) either infected with Epichloë endophyte $(\mathrm{E}+)$ or uninfected $(\mathrm{E}-)$ were grown in the field. The activities of the antioxidant enzymes ascorbate peroxidase, catalase, peroxidase and superoxide dismutase, and concentrations of $\mathrm{H}_{2} \mathrm{O}_{2}$ and malondialdehyde were examined in the leaves of $\mathrm{E}+$ and $\mathrm{E}-$ plants. We also determined photosynthesis parameters, leaf blade and sheath carbohydrate concentration and plant growth parameters of both $\mathrm{E}+$ and $\mathrm{E}-$ plants. $\mathrm{E}+$ plants from the WLS and QY populations had significantly higher antioxidant enzyme activities and photosynthetic capability $(P<0.05)$, superior growth characteristics including more abundant carbohydrate concentration than E- plants. In contrast, in plants from the WTS population, the endophyte had no significant effect on reactive oxygen species scavenging capability and growth performance $(P>0.05)$, and even displayed some negative effects on plant photosynthetic capability. Thus, endophyte infection significantly affected E. dahuricus antioxidant enzyme activities $(P<0.05)$, photosynthesis and growth capability, although, the effects varied with plant ecotypes.
\end{abstract}

Keywords antioxidant enzymes, Elymus dahuricus, Epichloë, fungal endophyte, photosynthesis

\section{Introduction}

Fungal endophytes are fungi that live for a significant part

Received August 30, 2017; accepted November 7, 2017

Correspondence: zhibiao@1zu.edu.cn of their life cycle internally and asymptomatically in plants $^{[1,2]}$. Many cool-season grass species have seedtransmitted fungal endophytes that grow systemically in the intercellular spaces of aboveground tissues. Generally, these associations are considered as mutualistic ${ }^{[1-3]}$. It has been reported that endophytes can increase the resistance of host to biotic ${ }^{[4-6]}$ and abiotic stresses ${ }^{[7-9]}$. However, increasing evidence suggests that the outcome of the interaction depends on the particular circumstances $^{[10-12]}$, host genotype and ecotype and endophyte haplotype ${ }^{[10,13-15]}$.

The increased production of toxic oxygen derivatives is an outcome of both natural and stress situations ${ }^{[7,16]}$. These highly cytotoxic reactive oxygen species (ROS) can seriously disrupt normal metabolism through oxidative damage to cellular components ${ }^{[17]}$. One possible mechanism of scavenging ROS is the production of antioxidant enzymes including ascorbate peroxidase (APX), catalase (CAT), peroxidase (POD) and superoxide dismutase (SOD) ${ }^{[18]}$. The presence of Epichloë endophyte in ryegrass (Lolium perenne cv. Apollo) led to an increase in the threshold toxicity of zinc by a diminution of APX activity ${ }^{[19]}$. Also, an increase in ROS-scavenging enzymes was shown in drought-stressed Elymus dahuricus, a forage species common in dry areas ${ }^{[20]}$. Interestingly, fungal reactive oxygen species are critical for maintaining a mutualistic fungus-plant interaction ${ }^{[21]}$.

Results of early studies of the effects of endophytes upon physiological processes were equivocal. The presence of an endophyte may cause decreased rates of photosynthesis ${ }^{[22]}$. However, because the endophyte does not possess nutrient-absorbing structures and utilizes apoplasmic nutrients that have diffused out of the cytoplasm $^{[1]}$, photosynthetic rates would not be expected to increase due to the presence of an endophyte ${ }^{[23]}$. However, endophyte-infected plants may be able to maintain water-use efficiency through enhanced leaf rolling, which reduces water loss, and so should increase 
photosynthetic rates of host grass under drought ${ }^{[24]}$ and high temperature stresses ${ }^{[25]}$. Moreover, elevated $\mathrm{CO}_{2}$ and nitrogen can impact on photosynthesis of an endophytegrass association ${ }^{[26]}$. However, endophyte infection had no effect on the light interception and conversion processes of photosynthesis, supported by the lack of a difference in apparent photon yield between endophyte-infected $(\mathrm{E}+)$ and uninfected $(\mathrm{E}-)$ plants ${ }^{[27]}$.

While the ecological significance of fungal endophytes of the agronomically-important grasses, L. perenne and Festuca arundinacea, is well documented, the ecological significance of endophytes in wild grasses are not so well understood $^{[2,3]}$. E. dahuricus is a perennial caespitose grass with wide geographical distribution in arid and semi-arid regions of China and neighboring countries. In the 1970s, it was cultivated in north and north-east China, and in Inner Mongolia ${ }^{[8]}$. In China, E. dahuricus grows at a range of densities on temperate rangelands, usually mixed with other grasses and legumes. It is an important grass for rangeland rehabilitation in the degradation grassland zone of northern China, and its use can reduce wind erosion and land desertification ${ }^{[28]}$.

E. dahuricus is known for its wide adaptation and is recommended for mixtures with other saline tolerant grasses to promote rapid stand establishment and ground cover $^{[8,28]}$. It was reported that the frequency of Epichloë spp. infected plants in E. dahuricus ranged from $0 \%$ to $100 \%$ in 26 populations in $\mathrm{China}^{[8,29]}$, and that the alkaloid peramine was produced in the leaf sheaths of three populations of $\mathrm{E}+$ plants. This alkaloid has feeding deterrence effects on some insect pests ${ }^{[4,30,31]}$. In E. cylindricus, endophytes can increase the number of tillers and dry matter yield per plant in the field ${ }^{[32]}$.

Our previous study indicated Epichloë endophyte infection was a benefit to growth of and antioxidative effects in E. dahuricus under low water treatment in a controlled-environment experiment ${ }^{[29]}$. The objective of the study reported here was to investigate the effects of Epichloe endophyte infection on different ecotypes of E. dahuricus under field conditions. We focused on ROS scavenging capability, photosynthesis and carbohydrate production, as well as basic growth parameters. It was predicted that $\mathrm{E}+$ E. dahuricus would have superior characteristics, as mentioned above, compared to E- plants under field conditions.

\section{Materials and methods}

\subsection{Plant material}

Seeds from wild E. dahuricus populations WLS (Wulingshan, China, $\left.116.50^{\circ} \mathrm{E}, 40.37^{\circ} \mathrm{N}, 2118 \mathrm{~m}\right)$ were collected in September 2002, QY (Qinyuan, China, 112.21 ${ }^{\circ} \mathrm{E}$, $36.31^{\circ} \mathrm{N}, 1000 \mathrm{~m}$ ) and WTS (Wutaishan, China, $113.32^{\circ}$ E, $39.02^{\circ} \mathrm{N}, 2896 \mathrm{~m}$ ) were collected in September
2003 and were tested for Epichloë spp. infection by microscopically examining leaf sheaths stained with aniline blue ${ }^{[33]}$. The infection frequencies were about $100 \%, 31 \%$ and $73 \%$, respectively.

Seeds of these were sown in May 2004 in plastic pots $(30 \mathrm{~cm} \times 25 \mathrm{~cm} \times 8 \mathrm{~cm})$ that were filled with soil $(1 \mathrm{~kg})$ that had been sterilized in an oven at $160^{\circ} \mathrm{C}$ for $6 \mathrm{~h}$. Only well-filled, apparently-healthy seeds were used for this experiment. Five rows with 10 seeds per row were planted per pot at a depth of $5 \mathrm{~mm}$. Pots were placed in a temperature-controlled greenhouse $\left(18-24^{\circ} \mathrm{C}\right)$ with $10 \mathrm{~h}$ illumination per day. Each day pots were watered with $90 \mathrm{~mL}$ water. After four weeks, the percentage infection of plants infected with endophyte was determined by examining leaf sheaths stained with aniline blue. Despite the seed of the WLS ecotype having been $100 \%$ infected with endophyte, some of the examined seedlings were endophyte-free, a likely consequence of two years of storage. On July 23, 2004, they were transplanted at $2.4 \mathrm{~m}$ $\times 2.5 \mathrm{~m}$ into the field plots located at the Yuzhong Campus of Lanzhou University at an elevation of $1517 \mathrm{~m}$ above sea level. The soil nutritient concentration were $0.072 \%$ total phosphorus, $0.34 \%$ total nitrogen, $2.13 \%$ total potassium, $9.39 \mathrm{mg} \cdot \mathrm{kg}^{-1}$ available phosphorus, $96 \mathrm{mg} \cdot \mathrm{kg}^{-1}$ available nitrogen, and $282 \mathrm{mg} \cdot \mathrm{kg}^{-1}$ available potassium, and the $\mathrm{pH}$ was 7.7 and salt $0.05 \%$. Plants were watered daily for the first week after being transplanted to assistant establishment and then not watered. Each pair of plants were approximately the same size, consisting of four to six tillers each. The final stable numbers were about 50 uninfected and 50 infected plants. Twenty $\mathrm{E}+$ and $\mathrm{E}-$ plants from each populations were labeled.

On June 3, a sunny day, the photosynthetic parameters were determined. Plant height and tiller number of the labeled plants were recorded on the third day of every second month during the growing season in 2005. In addition, five tillers of each labeled plant were cut and the dry weight was determined after drying them at $80^{\circ} \mathrm{C}$ for $48 \mathrm{~h}$ in a forced-air oven. Then the tillers were split into stem and leaf and weighed for stem/leaf ratio, and then ground to a fine powder for determination of carbohydrate concentrations. Another two tillers of each labeled plant were cut. Parts of fresh leaves were used to extract and assay enzymes immediately, and other leaves were plunged for $2 \mathrm{~min}$ in liquid nitrogen, freeze-dried at $-60^{\circ} \mathrm{C}$, then ground to a fine powder in a mortar, stored at $-80^{\circ} \mathrm{C}$ for photosynthetic pigments concentration determination. Finally, at the end of the growing season (October), all above-ground parts of labeled plants were collected and the biomass production of each strain was determined after drying them at $80^{\circ} \mathrm{C}$ for $48 \mathrm{~h}$ in a forcedair oven.

\subsection{Extraction and assay of enzymes}

To extract antioxidant enzymes, fresh leaves $(0.5 \mathrm{~g})$ were 
homogenized in $5 \mathrm{~mL}$ of $50 \mathrm{mmol} \cdot \mathrm{L}^{-1}$ sodium phosphate buffer (pH 7 for CAT and $\mathrm{pH} 7.8$ for SOD, POD and APX) containing $1 \%(\mathrm{w} / \mathrm{v}) \mathrm{PVP}$ and $0.1 \mathrm{mmol} \cdot \mathrm{L}^{-1} \mathrm{Na}_{2}$ EDTA. The homogenate was filtered through four layers of cheesecloth and centrifuged at $15000 \mathrm{~g}$ for $15 \mathrm{~min}$. After centrifugation, aliquots of the supernatant were used to determine the enzyme activities and protein concentration. All extractions were prepared at $4^{\circ} \mathrm{C}$, and enzyme assays were performed at $25^{\circ} \mathrm{C}$.

The SOD activity was measured spectrophotometrically as described by Beyer and Fridovich ${ }^{[34]}$. CAT activity was assayed by measuring the decline in absorbance at $240 \mathrm{~nm}$ because of the decomposition of $\mathrm{H}_{2} \mathrm{O}_{2}{ }^{[35]}$. POD activity was determined by the method of Chance and Maehly ${ }^{[36]}$ using guaiacol as an electron donor. APX activity was determined according to the method of Gupta et al. ${ }^{[37]}$ by measuring the oxidation of ascorbate at $290 \mathrm{~nm}$. Protein concentration in the enzymatic extraction was measured by the method of Bradford ${ }^{[38]}$.

$\mathrm{H}_{2} \mathrm{O}_{2}$ was determined according to the method of Velikova et al. ${ }^{[39]}$. Leaf tissues $(0.5 \mathrm{~g})$ were homogenized in an ice bath with $10 \mathrm{~mL}$ TCA $(0.1 \%)$. The homogenate was centrifuged at $15000 \mathrm{~g}, 15 \mathrm{~min}$. One $\mathrm{mL}$ supernatant was added to $1 \mathrm{~mL}$ sodium phosphate buffer $\left(10 \mathrm{mmol} \cdot \mathrm{L}^{-1}\right.$, $\mathrm{pH} 7.0)$ and $2 \mathrm{~mL} \mathrm{KI}\left(1 \mathrm{~mol} \cdot \mathrm{L}^{-1}\right)$. The absorption of the reaction solution supernatant was measured at $390 \mathrm{~nm}$.

\subsection{Photosynthesis parameters}

Photosynthetic parameters including net rate of photosynthesis, stomatal conductance, transpiration rate and intercellular $\mathrm{CO}_{2}$ concentration were measured using a LI6400 XT Portable Photosynthesis System (LI-COR Inc., Lincoln, NE, USA) on five of the 20 labeled plants.

\subsection{Photosynthetic pigments concentrations}

Frozen ground leaf powder $(0.1 \mathrm{~g})$ was used to determine photosynthetic pigment concentrations. Total chlorophyll and carotenoid concentration were measured in $80 \%$ acetone extracts and calculated using the extinction coefficients determined by Lichtenthaler and Wellburn ${ }^{[40]}$.

\subsection{Soluble sugar and starch concentration}

About $100 \mathrm{mg}$ of the dried samples described above were homogenized in $10 \mathrm{~mL}$ of $80 \%$ ethanol and placed in a water bath at $80^{\circ} \mathrm{C}$ for $30 \mathrm{~min}$, then centrifuged at $22000 \mathrm{~g}$ for $20 \mathrm{~min}$. Samples were extracted three times, and their supernatants pooled and volumes reduced to $3 \mathrm{~cm}^{3}$ by evaporation before diluting to $25 \mathrm{~mL}$ with water. Sugars were estimated in ethanolic extracts. For starch extraction, residues left in the centrifuge tubes after sugar extraction were oven-dried at $80^{\circ} \mathrm{C}$ for $24 \mathrm{~h}$. After addition of $2 \mathrm{~mL}$ of water, tubes were placed in a boiling water bath for $15 \mathrm{~min}$ and after cooling, $2 \mathrm{~mL}$ of $9.2 \mathrm{~mol} \cdot \mathrm{L}^{-1}$ perchloric acid
(PCA) was added. The contents were stirred for $15 \mathrm{~min}$ and volumes were made up to $10 \mathrm{~mL}$ with water. Supernatants were collected after centrifuging the contents at $3000 \mathrm{~g}$ for $20 \mathrm{~min}$. Residues were re-extracted twice with $2 \mathrm{~mL}$ of $4.6 \mathrm{~mol} \cdot \mathrm{L}^{-1} \mathrm{PCA}$. After centrifugation, the supernatants were combined and volume adjusted to $50 \mathrm{~mL}$ with water. Total soluble sugar and starch concentrations were estimated colorimetrically using the phenol-sulphuric acid method of Dubois et al. ${ }^{[41]}$.

\subsection{Statistical analysis}

Analysis of variance was used to examine the effects of endophyte and ecotypes (WLS, QY and WTS) on biomass, growth and photosynthetic parameters, and least significant difference tests were used to compare individual means. SPSS version 15.0 (IBM Corporation, Armonk, NY, USA) was used to determine the statistical significance of the results when comparing SOD, POD, CAT, APX, chlorophyll $(a+b)$, carotenoid, and carbohydrate concentration of the different ecotypes and plants with and without endophyte infection.

\section{Results}

\subsection{Growth characteristics}

Plant height, tiller number and weight were determined every two months during the growing season of 2005 . These parameters were all significantly higher in $\mathrm{E}+$ than $\mathrm{E}-$ plants from the WLS and QY populations $(P<0.05)$ (Table 1). However, no significant differences were found between $\mathrm{E}+$ and $\mathrm{E}-$ plants from the WTS population.

At the end of the growing season, the above-ground portion was harvested to determine dry matter. There was significantly greater above-ground biomass production in $\mathrm{E}+$ than E- plants from the WLS and QY populations, being 1.63 and 4.96 times greater, respectively $(P<0.05)$ (Table 1). No difference was observed between $\mathrm{E}+$ and $\mathrm{E}-$ plants from the WTS population.

\subsection{Toxic reactive oxygen species concentration}

At all time points tested, $\mathrm{H}_{2} \mathrm{O}_{2}$ and malondialdehyde (MDA) concentrations were significant higher in $\mathrm{E}$ - plants than in E+ plants from the WLS and QY populations $(P<0.05)$ (Table 2). There were no significant differences in the $\mathrm{H}_{2} \mathrm{O}_{2}$ and MDA concentrations in plants from the WTS population.

\subsection{Antioxidant enzyme activities}

Endophyte infection increased ROS activity in plants from the WLS and QY populations. SOD, POD, CAT and APX activities were significantly higher in $\mathrm{E}+$ than $\mathrm{E}$ - plants on 
Table 1 Growth characteristics of E. dahuricus infected with (E+) or without (E-) grass endophyte

\begin{tabular}{|c|c|c|c|c|c|c|c|c|}
\hline \multirow{3}{*}{ Measurements } & \multirow{3}{*}{ Date } & \multicolumn{6}{|c|}{ Ecotypes of E. dahuricus } & \multirow{3}{*}{$\mathrm{LSD}_{0.05}$} \\
\hline & & \multicolumn{2}{|c|}{ WLS } & \multicolumn{2}{|c|}{ QY } & \multicolumn{2}{|c|}{ WTS } & \\
\hline & & $\mathrm{E}+$ & E- & $\mathrm{E}+$ & E- & E+ & $\mathrm{E}-$ & \\
\hline \multirow[t]{3}{*}{ Plant height $/ \mathrm{cm}$} & Jun. 3 & 24.7 & 19.0 & 29.7 & 18.1 & 18.78 & 18.7 & 3.3 \\
\hline & Aug. 3 & 40.9 & 21.1 & 37.3 & 16.4 & 24.8 & 23.1 & 5.7 \\
\hline & Oct. 3 & 51.4 & 31.3 & 51.7 & 32.2 & 29.9 & 27.5 & 10.2 \\
\hline \multirow[t]{3}{*}{ Tiller number/plant } & Jun. 3 & 3.9 & 2.0 & 3.8 & 2.1 & 3.0 & 2.6 & 0.7 \\
\hline & Aug. 3 & 3.2 & 1.8 & 3.6 & 1.9 & 2.7 & 2.5 & 0.8 \\
\hline & Oct. 3 & 3.6 & 1.8 & 4.8 & 1.9 & 2.5 & 3.0 & 1.0 \\
\hline \multirow[t]{3}{*}{ Dry weight/g } & Jun. 3 & 0.78 & 0.31 & 0.82 & 0.29 & 0.31 & 0.37 & 0.12 \\
\hline & Aug. 3 & 2.14 & 0.77 & 1.59 & 0.70 & 1.22 & 1.19 & 0.19 \\
\hline & Oct. 3 & 0.70 & 0.21 & 0.29 & 0.16 & 0.09 & 0.09 & 0.11 \\
\hline
\end{tabular}

Note: WLS, Wulingshan, Beijing, China; QY, Qinyuan, Shanxi Province, China; WTS, Wutaishan, Shanxi Province, China.

Table 2 Toxic reactive oxygen species (ROS) concentration in fresh leaves of $E$. dahuricus infected with (E+) or without (E-) grass endophyte

\begin{tabular}{|c|c|c|c|c|c|c|c|c|}
\hline \multirow{3}{*}{ Measurement } & \multirow{3}{*}{ Date } & \multicolumn{6}{|c|}{ Ecotypes of E. dahuricus } & \multirow{3}{*}{$\mathrm{LSD}_{0.05}$} \\
\hline & & \multicolumn{2}{|c|}{ WLS } & \multicolumn{2}{|c|}{ QY } & \multicolumn{2}{|c|}{ WTS } & \\
\hline & & $\mathrm{E}+$ & E- & $\mathrm{E}+$ & $\mathrm{E}-$ & $\mathrm{E}+$ & E- & \\
\hline \multirow[t]{3}{*}{$\mathrm{H}_{2} \mathrm{O}_{2} /\left(\mathrm{mmol} \cdot \mathrm{g}^{-1}\right)$} & Jun. 3 & 13.3 & 25.5 & 17.2 & 26.7 & 25.1 & 20.1 & 6.1 \\
\hline & Aug. 3 & 16.7 & 53.7 & 14.4 & 46.6 & 35.6 & 35.3 & 9.1 \\
\hline & Oct. 3 & 33.1 & 99.0 & 41.6 & 94.5 & 80.7 & 76.0 & 11.6 \\
\hline \multirow[t]{3}{*}{$\mathrm{MDA} /\left(\mu \mathrm{mol} \cdot \mathrm{g}^{-1}\right)$} & Jun. 3 & 0.77 & 1.09 & 0.51 & 0.66 & 0.80 & 0.76 & 0.10 \\
\hline & Aug. 3 & 0.66 & 1.16 & 0.78 & 0.91 & 0.85 & 0.83 & 0.14 \\
\hline & Oct. 3 & 0.76 & 1.00 & 0.65 & 0.96 & 0.81 & 0.72 & 0.12 \\
\hline
\end{tabular}

Note: WLS, Wulingshan, Beijing, China; QY, Qinyuan, Shanxi Province, China; WTS, Wutaishan, Shanxi Province, China.

all sampling dates $(P<0.05$, Table 3$)$. Significant differences in antioxidant enzyme activities in $\mathrm{E}-$ and $\mathrm{E}+$ plants from the WTS population were only observed for CAT and APX activities in August.

\subsection{Photosynthetic capacity}

Photosynthetic capacity were tested on June 3, and the environmental conditions at every sampling date are summarized in Table 4. The trends in NRP (net rate of photosynthesis), ICC (intercellular $\mathrm{CO}_{2}$ concentration) and LC (leaf conductance) in plants from the three populations were consistent. They all increased from 7:30, peaking at 11:30 before declining sharply and reaching the lowest daytime value at 13:30, then rising again before finally decreasing from 15:30. TR (transpiration rate) in WTS population had the same shape as the three parameters described above, and in plants from WLS and QY populations, TR peaked at 15:30. NRP and ICC in E+ plants from the three populations were equivalent, while LC and TR were the highest in plants from the WLS population and lowest in plants from the QY population. The four parameters in E- plants were ranked as WTS >

\section{QY $>$ WLS.}

For plants from the WLS and QY populations, the photosynthetic parameters for $\mathrm{E}+$ plants were all significantly higher at all time points than those of E- plants $(P<0.05$, Fig. 1$)$, while in plants from the WTS population, $\mathrm{E}+$ and $\mathrm{E}-$ plants had equivalent NRP and ICC. LC and TR were higher in E+ compared to E- plants at every time point, and significant differences were found in $\mathrm{LC}$ at 7:30, 9:30 and 13:30, and in TR at 9:30 and 13:30 $(P<0.05)$.

\subsection{Leaf photosynthetic pigments}

Chlorophyll $(\mathrm{a}+\mathrm{b})$ and carotenoid concentrations were significantly higher in $\mathrm{E}+$ compared to $\mathrm{E}$ - plants from the WLS and QY populations $(P<0.05$, Table 4$)$. This trend was reversed in plants from the WTS population with Eplants having higher photosynthetic pigment concentrations than $\mathrm{E}+$ plants which was significant in October.

\subsection{Carbohydrates concentration}

Both soluble sugar and starch concentrations peaked at the 
Table 3 Antioxidant enzyme activities in fresh leaves of E. dahuricus infected with (E+) or without (E-) grass endophyte

\begin{tabular}{|c|c|c|c|c|c|c|c|c|}
\hline \multirow{3}{*}{ Measurements } & \multirow{3}{*}{ Date } & \multicolumn{6}{|c|}{ Ecotypes of $E$. dahuricus } & \multirow{3}{*}{$\mathrm{LSD}_{0.05}$} \\
\hline & & \multicolumn{2}{|c|}{ WLS } & \multicolumn{2}{|c|}{ QY } & \multicolumn{2}{|c|}{ WTS } & \\
\hline & & $\mathrm{E}+$ & $\mathrm{E}-$ & $\mathrm{E}+$ & $\mathrm{E}-$ & $\mathrm{E}+$ & E- & \\
\hline \multirow[t]{3}{*}{ Superoxide dismutase(SOD)/(U· $\left.\mathrm{mg}^{-1}\right)$} & Jun. 3 & 24.4 & 13.2 & 28.6 & 18.1 & 19.9 & 22.5 & 2.7 \\
\hline & Aug. 3 & 32.7 & 18.7 & 29.0 & 14.0 & 19.7 & 22.4 & 5.0 \\
\hline & Oct. 3 & 54.3 & 21.7 & 47.5 & 17.7 & 26.0 & 28.1 & 6.9 \\
\hline \multirow[t]{3}{*}{ Peroxidase $(\mathrm{POD}) /\left(\mathrm{U} \cdot \mathrm{mg}^{-1}\right)$} & Jun. 3 & 25.3 & 12.4 & 33.9 & 23.3 & 23.6 & 28.3 & 6.2 \\
\hline & Aug. 3 & 28.8 & 9.6 & 28.4 & 16.2 & 14.3 & 17.0 & 6.3 \\
\hline & Oct. 3 & 54.8 & 28.6 & 55.7 & 23.0 & 40.3 & 42.2 & 14.9 \\
\hline \multirow[t]{3}{*}{ Catalase $(\mathrm{CAT}) /\left(\mathrm{U} \cdot \mathrm{mg}^{-1}\right)$} & Jun. 3 & 1.13 & 0.32 & 1.03 & 0.37 & 0.6 & 0.79 & 0.34 \\
\hline & Aug. 3 & 2.70 & 1.11 & 3.20 & 1.44 & 1.25 & 1.85 & 0.59 \\
\hline & Oct. 3 & 6.63 & 2.04 & 7.05 & 3.04 & 5.45 & 6.17 & 0.76 \\
\hline \multirow[t]{3}{*}{ Ascorbate peroxidase $(\mathrm{APX}) /\left(\mathrm{U} \cdot \mathrm{mg}^{-1}\right)$} & Jun. 3 & 0.43 & 0.15 & 0.30 & 0.14 & 0.28 & 0.41 & 0.11 \\
\hline & Aug. 3 & 0.74 & 0.26 & 0.80 & 0.27 & 0.32 & 0.48 & 0.13 \\
\hline & Oct. 3 & 1.89 & 0.64 & 1.99 & 0.55 & 1.29 & 1.42 & 0.25 \\
\hline
\end{tabular}

Note: WLS, Wulingshan, Beijing, China; QY, Qinyuan, Shanxi Province, China; WTS, Wutaishan, Shanxi Province, China.

Table 4 Leaf photosynthetic pigments content of E. dahuricus infected with (E+) or without (E-) grass endophyte

\begin{tabular}{|c|c|c|c|c|c|c|c|c|}
\hline \multirow{3}{*}{ Variety } & \multirow{3}{*}{ Month } & \multicolumn{6}{|c|}{ Ecotypes of E. dahuricus } & \multirow{3}{*}{$\mathrm{LSD}_{0.05}$} \\
\hline & & \multicolumn{2}{|c|}{ WLS } & \multicolumn{2}{|c|}{ QY } & \multicolumn{2}{|c|}{ WTS } & \\
\hline & & E+ & $\mathrm{E}-$ & E+ & E- & $\mathrm{E}+$ & $\mathrm{E}-$ & \\
\hline \multirow[t]{3}{*}{ Chlorophyll $(\mathrm{a}+\mathrm{b})$} & Jun. & 7.52 & 5.86 & 7.54 & 5.94 & 6.55 & 7.14 & 1.04 \\
\hline & Aug. & 5.64 & 4.90 & 5.48 & 4.72 & 4.97 & 5.29 & 0.63 \\
\hline & Oct. & 3.30 & 2.48 & 4.18 & 3.73 & 3.93 & 4.99 & 0.27 \\
\hline \multirow[t]{3}{*}{ Carotenoid } & Jun. & 104.7 & 87.8 & 95.6 & 80.9 & 95.4 & 106.6 & 14.1 \\
\hline & Aug. & 50.3 & 28.5 & 54.6 & 37.3 & 40.4 & 44.1 & 14.8 \\
\hline & Oct. & 72.9 & 50.3 & 60.1 & 53.2 & 58.8 & 72.1 & 5.2 \\
\hline
\end{tabular}

Note: WLS, Wulingshan, Beijing, China; QY, Qinyuan, Shanxi Province, China; WTS, Wutaishan, Shanxi Province, China.

end of the growing season (Table 5). E+ plants from the WLS and QY populations had significantly higher leaf blade and sheath soluble sugar and starch concentrations than $\mathrm{E}-$ plants on all sampling dates $(P<0.05)$. In contrast, in plants from the WTS population, all carbohydrate concentrations were higher in $\mathrm{E}-$ than $\mathrm{E}+$ plants. No significance was observed in leaf soluble sugar and starch concentrations between $\mathrm{E}+$ and $\mathrm{E}-$ plants. Both leaf blade and sheath starch concentrations in $\mathrm{E}+$ plants were significantly higher than in $\mathrm{E}-$ plants at the end of the growing season $(P<0.05)$. In plants from the three populations, both soluble sugar and starch concentrations were higher in leaf sheaths than in leaf blades.

\section{Discussion}

Our results indicate that the effect of endophyte infection varies among the three ecotypes. In plants from the WLS and QY populations, the endophyte increased the antioxidative enzyme activities, photosynthetic capability and carbohydrate concentrations, and enhanced host growth. However, the endophyte had no positive effect on those parameters in plants from the WTS population, and even reduced some. This suggests that interactions between host plants and endophytes can be quite variable depending both on environmental conditions and host genotypes, and this interaction can vary from mutualistic to antagonistic.

\subsection{Toxic reactive oxygen species concentration and scavenging capability were affected by endophyte and ecotype}

ROS are well-known indicators of stress in many organisms. Excessive toxic ROS including superoxide radicals $\left(\mathrm{O}_{2}^{-}\right), \mathrm{H}_{2} \mathrm{O}_{2}$ and hydroxyl radicals $\left(\mathrm{OH}^{-}\right)$can seriously disrupt normal metabolism through oxidative damage to cellular components ${ }^{[18]}$. One of the most 


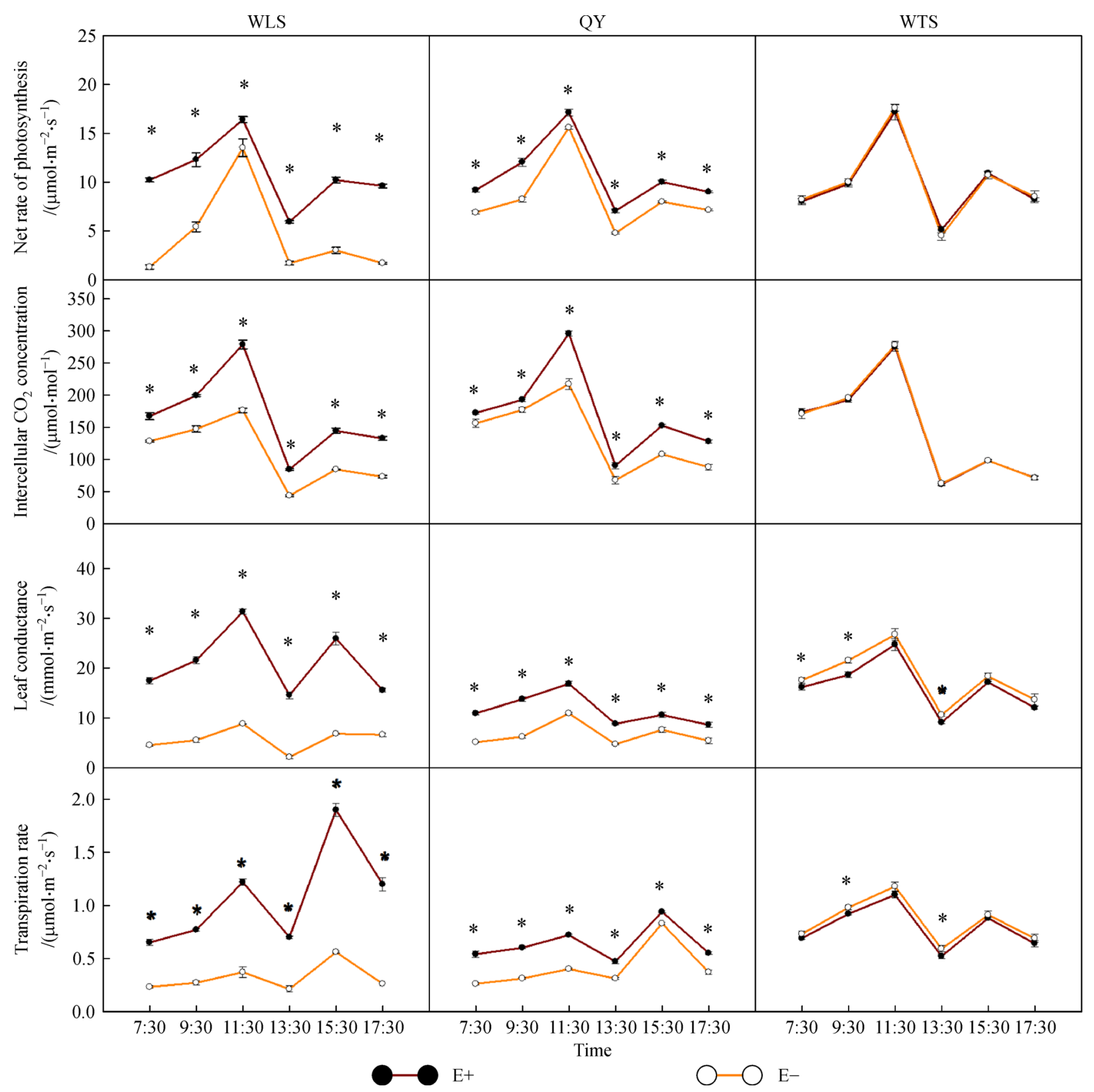

Fig. 1 Photosynthetic capability of Elymus dahuricus infected with (E+ ) or without (E-) grass endophyte. *, indicate significant difference between $\mathrm{E}+$ and $\mathrm{E}-$ plants at $P<0.05$. Bars indicate S.E. $(n=5)$.

damaging effects of these molecular species, and their products in cells, is the peroxidation of membrane lipids ${ }^{[42]}$. Bonnet et al. ${ }^{[19]}$ found the presence of the endophyte, Epichloë lolii, modified the metabolism of ryegrass ( $L$. perenne cv. Apollo) by favoring $\mathrm{H}_{2} \mathrm{O}_{2}$ scavenging throughout the catalase process, and improved the defense capability of the host. Also, an increase in ROS-scavenging enzymes was shown in drought-stressed E. dahuricus, a forage species common in dry areas ${ }^{[33]}$. These enzymes were significantly more abundant in plants containing endophytes than in endophyte-free plants, although it is not known if they were of plant or fungal origin. Our results were similar; the presence of endophyte could affect E. dahuricus toxic ROS concentrations and ROS scavenging capability, though the effects varied with different ecotypes. The SOD gene of $E$. lolii has been isolated ${ }^{[43]}$ and provides a new probe to investigate the role of gene expression in ROS-scavenging capability and the mechanism of the interaction between endophyte and plant.

4.2 Both Photosynthesis capability and pigments concentrations were modified by endophyte and ecotype

Our results indicated that endophyte infection affects E. dahuricus photosynthesis capability, but the effects 
Table 5 Leaf and sheath carbohydrates content of E. dahuricus infected with (E+ ) or without (E-) grass endophyte $\left(\mathrm{g} \cdot \mathrm{kg}^{-1} \mathrm{DW}\right)$

\begin{tabular}{|c|c|c|c|c|c|c|c|c|}
\hline \multirow{3}{*}{ Varieties } & \multirow{3}{*}{ Month } & \multicolumn{6}{|c|}{ Ecotypes E. dahuricus } & \multirow{3}{*}{$\mathrm{LSD}_{0.05}$} \\
\hline & & \multicolumn{2}{|c|}{ WLS } & \multicolumn{2}{|c|}{ QY } & \multicolumn{2}{|c|}{ WTS } & \\
\hline & & $\mathrm{E}+$ & $\mathrm{E}-$ & $\mathrm{E}+$ & E- & $\mathrm{E}+$ & $\mathrm{E}-$ & \\
\hline \multirow[t]{3}{*}{ Leaf soluble sugar } & Jun. & 36.7 & 17.8 & 34.7 & 12.7 & 25.9 & 24.0 & 4.0 \\
\hline & Aug. & 65.2 & 48.5 & 44.2 & 18.8 & 27.3 & 32.1 & 7.1 \\
\hline & Oct. & 121.2 & 43.2 & 116.1 & 52.1 & 58.3 & 50.3 & 12.5 \\
\hline \multirow[t]{3}{*}{ Sheath soluble sugar } & Jun. & 97.6 & 73.8 & 95.0 & 50.5 & 91.8 & 82.0 & 13.3 \\
\hline & Aug. & 200.1 & 136.4 & 114.1 & 77.6 & 117.4 & 110.8 & 7.9 \\
\hline & Oct. & 256.2 & 157.0 & 238.3 & 157.1 & 157.0 & 208.3 & 26.3 \\
\hline \multirow[t]{3}{*}{ Leaf starch } & Jun. & 59.3 & 36.8 & 72.4 & 34.6 & 66.2 & 73.7 & 11.9 \\
\hline & Aug. & 182.9 & 110.6 & 185.1 & 108.9 & 127.4 & 139.0 & 14.6 \\
\hline & Oct. & 196.7 & 112.3 & 195.1 & 122.2 & 184.0 & 187.1 & 13.1 \\
\hline \multirow[t]{3}{*}{ Sheath starch } & Jun. & 180.9 & 96.0 & 164.1 & 105.5 & 169.6 & 176.3 & 21.5 \\
\hline & Aug. & 189.4 & 112.5 & 221.0 & 171.3 & 220.3 & 236.8 & 30.6 \\
\hline & Oct. & 190.0 & 121.9 & 192.3 & 141.1 & 172.3 & 225.0 & 16.5 \\
\hline
\end{tabular}

Note: WLS, Wulingshan, Beijing, China; QY, Qinyuan, Shanxi Province, China; WTS, Wutaishan, Shanxi Province, China.

varied between ecotypes. WLS and QY E+ plants had significantly stronger net photosynthetic rate, intercellular $\mathrm{CO}_{2}$ concentration, leaf conductance and transpiration rate. This is consistent with other results on different host species. Marks and Clay ${ }^{[25]}$ used F. arundinacea cv. Kentucky 31 to study the physiological responses to fungal endophyte infection, and found at leaf temperatures above $35^{\circ} \mathrm{C}$ infected plants photosynthesized at a significantly greater rate $(20 \%$ to $25 \%)$ than uninfected plants. Newman et al. ${ }^{[26]}$ used the same plants and found that endophyteinfected plants showed a $16 \%$ increase in photosynthetic rate under high-N conditions. Morse et al. ${ }^{[4]}$ also found that $\mathrm{E}+$ plants of $F$. arizonica had significantly higher net photosynthesis compared to $\mathrm{E}$ - plants under severe water limitation. Amalric et al. ${ }^{[45]}$ reported that E. lolii infected perennial ryegrass (cv. Apollo) had higher stomatal conductance, transpiration rate, net photosynthetic rate, and photorespiratory electron transport rates than the Eplants. From the above, it is clear that the effects induced by the presence of endophytes on host grass photosynthesis can be affected by host species and environment conditions.

In plants from the WTS population, endophyte infection had no effect on net photosynthetic rate and intercellular $\mathrm{CO}_{2}$ concentration, although leaf conductance and transpiration rates were higher in $\mathrm{E}-$ than $\mathrm{E}+$ plants. Others have observed similar results. Spiering et al. ${ }^{[27]}$ reported that endophyte-infected ryegrass had significantly lower light-saturated photosynthesis than E- plants, and also, endophyte infection decreased net photosynthesis at high light intensities but had no effect on apparent photon yield and dark respiration. Monnet et al. ${ }^{[4]}$ reported E. lolii favored maintenance of photosystem II activity in ryegrass, but did not significantly modify net photosynthesis. Also, Bacon ${ }^{[1]}$ reported that there was no endophyte effect of any consequence on photosynthesis and associated processes in several genotypes of infected $F$. arundinacea.

Photosynthetic pigments concentrations showed similar trends to photosynthetic capability. WLS and QY E+ plants had significant higher chlorophyll $(a+b)$ and carotenoid concentrations than $\mathrm{E}-$ plants, while in plant from the WTS population, E- plants had higher photosynthetic pigment concentration than $\mathrm{E}+$ plants. Others have also reported that endophyte infection can affect host photosynthetic pigments concentration. Rahman et al. ${ }^{[47]}$ found chlorophyll concentration in $F$. arundinacea was higher in $\mathrm{E}+$ than $\mathrm{E}-$ plants. Hunt et al ${ }^{[48]}$ reported that endophyte infection can affect the accumulation of chlorophyll concentration in perennial ryegrass. Increase in chlorophyll a can promote light interception and conversion and carbon assimilation. Our results indicate that endophyte infection enhanced leaf chlorophyll $(a+b)$ concentration in WLS and QY E+ plants. Under osmotic stress, the degradation of chlorophyll $(\mathrm{a}+\mathrm{b})$ was related to excessive active oxygen species such as $\mathrm{H}_{2} \mathrm{O}_{2}$, hydroxyl radicals and superoxide radicals, which cause oxidative damage of cell constituents ${ }^{[49]}$. Carotenoids are one of the main lipid-soluble antioxidants of plant cells, and they protect against photo-oxidation because they actively quench singlet oxygen $\left({ }^{1} \Delta_{\mathrm{g}} \mathrm{O}_{2}\right)$ and minimize its formation by absorbing excess energy from excited triplet states of chlorophyll ${ }^{[50]}$. Therefore, maintenance of high carotenoid concentration can enhance the ability of plants to eliminate reactive oxygen and reduce harmful oxidation effects. Photosynthetic pigments underpin photosynthesis and so these results for photosynthesis pigments can partially 
explain the results for photosynthetic capability shown above.

\subsection{Carbohydrate accumulation and plant growth characteristics}

Carbohydrate pools stored in tiller bases are important in grass regrowth ${ }^{[51]}$. Efficiency of mobilization and translocation of reserve carbohydrates could be more important than the actual level accumulated ${ }^{[52]}$. E + leaves and stems from the WLS and QY populations accumulated more soluble sugar and starch than E- plants, but this was not existed in the plants from the WTS population. Hill et al. ${ }^{[53]}$ found the effects of endophytes were different depending on the genotypes of host or species of endophytes, even under the same environmental conditions. Also, at the end of the growing season (October), WLS and QY E+ plants produced more soluble sugar and starch, which can decrease osmotic potential and enhance host adaption to low temperature and drought stress ${ }^{[54]}$. Accumulation of more carbohydrate enhances the ability of grasses to survive through the winter and to supply energy for regrowth in the next growing season. This phenomenon indicates $E$. dahuricus-endophyte associations might have some biochemical adaption mechanisms to natural selection pressure.

Both $\mathrm{E}+$ and $\mathrm{E}-$ plants had more carbohydrates in their leaf sheathes than in leaf blades, and this difference was greater in $\mathrm{E}+$ plants (Table 5). Plants have more endophytes in leaf sheathes than in leaf blades during the growing season ${ }^{[55]}$, which may be linked to the production of arabitol and mannitol ${ }^{[56]}$. This indicates that an endophyte might be able to stimulate the host to produce more monosaccharide in leaf sheaths, to the advantage of the plant.

Soluble sugar can decrease cell osmotic potential to maintain cell turgor pressure, resulting in excessive hydration of cells. Soluble sugar is regarded as essential for plant growth and respiration ${ }^{[57]}$, and is important for perennial grass respiration at the initial stage of re-growth, including re-growth after mowing or grazing, and from dormancy. Karsten and Macadam ${ }^{[58]}$ reported that the concentrations of six-carbon sugars and sucrose increased in ryegrass and $F$. arundinacea leaf sheaths during drought stress to decrease osmotic potential. Carbohydrates accumulation under non-drought condition and transport under water stress could increase drought tolerance of the endophyte-infected plant. Under normal conditions, some endophyte- $F$. arundinacea associations can produce more nonstructural carbohydrates than E- plants ${ }^{[53]}$, and when drought comes, those carbohydrates can be redistributed swiftly for adjustment of osmotic potential. Results of studies on the effects of endophyte on carbohydrates have been equivocal. Hardy et al. ${ }^{[59]}$ reported under wellwatered conditions, soluble sugar concentrations in leaves of $F$. arundinacea cv. Kentucky 31 were not affected by endophyte infection. Hill et al. ${ }^{[60]}$ reported a similar result for the same host under drought stress. Richardson et al. ${ }^{[56]}$ found that under drought conditions, endophyte-infected $F$. arundinacea accumulated more glucose and fructose. However, Hill et al. ${ }^{[53]}$ used five different genotypes of $F$. arundinacea as experiment material and found that $\mathrm{E}+$ leaves of three genotypes accumulated more nonstructural carbohydrates than E- leaves, for the rest of the two genotype, E- leaves had more or no significant difference nonstructural carbohydrates than leaves of $\mathrm{E}+$. This indicated the effect of endophytes varied between genotypes of particular host species.

Plant height and tiller number were significantly higher in WLS and QY E+ plants than E- plants at every sampling date, while no significant differences were found between $\mathrm{E}+$ and $\mathrm{E}-$ plants from the WTS population. This result is consistent with the results of previous research in our laboratory on Hordeum bodganii and E. cylindricus. In a greenhouse, endophyte infection enhanced growth of $H$. bodganii, compared with $\mathrm{E}-$ plants, and $\mathrm{E}+$ tiller number increased $137 \%{ }^{[61]}$. Tiller numbers of $E$. cylindricus $\mathrm{E}+$ plants were $85 \%$ higher than for $\mathrm{E}-$ plants $^{[32]}$. Endophytes can enhance host competition ability through promoting mineral nutrients and water absorption, therefore $\mathrm{E}+$ plants have better growth compared with $\mathrm{E}-$ plants ${ }^{[53,62]}$. Additionally, endophyte can induce some physical and biochemical changes to enhance plant competition. However, sometimes, the growth responses of $F$. arundinacea to endophyte infection depende on host ecotype and soil nutrient status ${ }^{[63]}$. Also, vegetative growth and nutrient acquisition in host grasses varied with ecotype and were modified by abiotic (soil fertility status) and biotic (endophyte infection) factors ${ }^{[47]}$.

\section{Conclusions}

Our results shed some light on the relationship between Epichloë endophyte and E. dahuricus of different ecotypes. Endophyte infection significantly increased antioxidant enzyme activities, photosynthetic pigment concentrations and total photosynthesis capability, as well as carbohydrate concentration and growth of E. dahuricus plants from the WTS and QY populations. However, Epichloë endophyte had no effect on most of those characteristics, or even displayed some antagonistic effects on some those parameters (e.g., leaf conductance, transpiration rate, and leaf and sheath starch concentration were significantly reduced by endophyte) in the WTS population. Thus, we conclude that endophyte infection affected E. dahuricus antioxidant enzyme activities, photosynthesis and growth capability, although, this varied with ecotype.

Acknowledgements This research was supported financially by the National Basic Research Program of China (2014CB138702). 
Compliance with ethics guidelines Yuping Zhang, Yanfei Zhou, Xingxu Zhang, Tingyu Duan, and Zhibiao Nan declare that they have no conflicts of interest or financial conflicts to disclose.

This article does not contain any studies with human or animal subjects performed by any of the authors.

\section{References}

1. Bacon C W. Abiotic stress tolerances (moisture, nutrients) and photosynthesis in endophyte-infected tall fescue. Agriculture, Ecosystems \& Environment, 1993, 44(1-4): 123-141

2. Kuldau G, Bacon C. Clavicipitaceous endophytes: their ability to enhance resistance of grasses to multiple stresses. Biological Control, 2008, 46(1): 57-71

3. Song H, Nan Z, Song Q, Xia C, Li X, Yao X, Xu W, Kuang Y, Tian $\mathrm{P}$, Zhang Q. Advances in research on Epichloë endophytes in Chinese native grasses. Frontiers in Microbiology, 2016, 7: 1399

4. Matsukura K, Shiba T, Sasaki T, Yoshida K, Matsumura M. Dynamics of Neotyphodium uncinatum and $\mathrm{N}$-formylloline in Italian ryegrass, and their relation to insect resistance in the field. Journal of Applied Microbiology, 2014, 116(2): 400-407

5. Ma M Z, Christensen M J, Nan Z B. Effects of the endophyte Epichloë festucae var. lolii of perennial ryegrass (Lolium perenne) on indicators of oxidative stress from pathogenic fungi during seed germination and seedling growth. European Journal of Plant Pathology, 2015, 141(3): 571-583

6. Pańka D, Piesik D, Jeske M, Baturo-Cieśniewska A. Production of phenolics and the emission of volatile organic compounds by perennial ryegrass (Lolium perenne L.)/Neotyphodium lolii association as a response to infection by Fusarium poae. Journal of Plant Physiology, 2013, 170(11): 1010-1019

7. Zhang X X, Fan X M, Li C J, Nan Z B. Effects of cadmium stress on seed germination, seedling growth and antioxidative enzym es in Achnatherum inebrians plants infected with a Neotyphodium endophyte. Plant Growth Regulation, 2010, 60(2): 91-97

8. Zhang Y P, Nan Z B. Germination and seedling anti-oxidative enzymes of endophyte-infected populations of Elymus dahuricus under osmotic stress. Seed Science and Technology, 2010, 38(2): $522-527$

9. Song M L, Chai Q, Li X Z, Yao X, Li C J, Christensen M J, Nan Z B. An asexual Epichloë endophyte modifies the nutrient stoichiometry of wild barley (Hordeum brevisubulatum) under salt stress. Plant and Soil, 2015, 387(1-2): 153-165

10. Müller C B, Krauss J. Symbiosis between grasses and asexual fungal endophytes. Current Opinion in Plant Biology, 2005, 8(4): $450-456$

11. Saikkonen K, Lehtonen P, Helander M, Koricheva J, Faeth S H. Model systems in ecology: dissecting the endophyte-grass literature. Trends in Plant Science, 2006, 11(9): 428-433

12. Iannone L J, Irisarri J G N, McCargo P D, Pérez L I, Gundel P E. Occurrence of Epichloe fungal endophytes in the sheep-preferred grass Hordeum comosum from Patagonia. Journal of Arid Environments, 2015, 115: 19-26

13. Saari S, Faeth S H. Hybridization of Neotyphodium endophytes enhances competitive ability of the host grass. New Phytologist,
2012, 195(1): 231-236

14. Vázquez-de-Aldana B R, García-Ciudad A, García-Criado B, Vicente-Tavera S, Zabalgogeazcoa I. Fungal endophyte (Epichloë festucae) alters the nutrient content of Festuca rubra regardless of water availability. PLoS One, 2013, 8(12): e84539

15. Jia T, Shymanovich T, Gao Y, Faeth S H. Plant population and genotype effects override the effects of Epichloë endophyte species on growth and drought stress response of Achnatherum robustum plants in two natural grass populations. Journal of Plant Ecology, 2015, 41(6): 3067-3075

16. Kampfenkel K, Van Montagu M, Inzé D. Effects of iron excess on Nicotiana plumbaginifolia plants (implications to oxidative stress). Plant Physiology, 1995, 107(3): 725-735

17. Halliwell B. Toxic effects of oxygen in plant tissues. In: Chloroplast Metabolism, The Structure and Function of Chloroplasts in Green Leaf Cells. Oxford: Oxford Press, 1984, 180-206

18. Hamilton C E, Bauerle T L. A new currency for mutualism? Fungal endophytes alter antioxidant activity in hosts responding to drought. Fungal Diversity, 2012, 54(1): 39-49

19. Bonnet M, Camares O, Veisseire P. Effects of zinc and influence of Acremonium lolii on growth parameters, chlorophyll a fluorescence and antioxidant enzyme activities of ryegrass (Lolium perenne L. cv Apollo). Journal of Experimental Botany, 2000, 51(346): 945-953

20. Zhang Y P, Nan Z B. Distribution of Epichloë endophytes in Chinese populations of Elymus dahuricus and variation in peramine levels. Symbiosis, 2007, 43(1): 13-19

21. Tanaka A, Christensen M J, Takemoto D, Park P, Scott B. Reactive oxygen species play a role in regulating a fungus-perennial ryegrass mutualistic interaction. Plant Cell, 2006, 18(4): 1052-1066

22. Belesky D P, Devine O J, Pallas J E. Photosynthetic activity of tall fescue as influenced by a fungal endophyte. Photosynthetica, 1987, 21(1): $82-87$

23. Richardson M D. The effect of endophyte removal on gas exchange in tall fescue. In: Proceedings of International Symposium on Acremonium/Grass Interactions. Baton Rouge: Louisiana Agriculture, 1990, 189-193

24. Xia C, Li N N, Zhang X X, Feng Y, Christensen M J, Nan Z B. An Epichloë endophyte improves photosynthetic ability and dry matter production of its host Achnatherum inebrians infected by Blumeria graminis under various soil water conditions. Fungal Ecology, 2016, 22: 26-34

25. Marks S, Clay K. Physiological responses of Festuca arundinacea to fungal endophyte infection. New Phytologist, 1996, 133(4): 727733

26. Newman J A, Abner M L, Dado R G, Gibson D J, Brookings A, Parsons A J. Effects of elevated $\mathrm{CO}_{2}$, nitrogen and fungal endophyte-infection on tall fescue: growth, photosynthesis, chemical composition and digestibility. Global Change Biology, 2003, 9 (3): 425-437

27. Spiering M J, Greer D H, Schmid J. Effects of the fungal endophyte, Neotyphodium lolii, on net photosynthesis and growth rates of perennial ryegrass (Lolium perenne) are independent of in planta endophyte concentration. Annals of Botany, 2006, 98(2): 379-387

28. Shao X Q, Wang K, Dong S K, Huang X X, Kang M Y. Regionalisation of suitable herbages for grassland reconstruction in agri-pastoral transition zone of northern China. New Zealand 
Journal of Agricultural Research, 2006, 49(1): 73-84

29. Zhang Y P, Nan Z B. Growth and anti-oxidative systems changes in Elymus dahuricus is affected by Neotyphodium endophyte under contrasting water availability. Journal Agronomy \& Crop Science, 2007, 193(6): 377-386

30. Shiba T, Sugawara K, Arakawa A. Evaluating the fungal endophyte Neotyphodium occultans for resistance to the rice leaf bug, Trigonotylus caelestialium, in Italian ryegrass, Lolium multiflorum. Entomologia Experimentalis et Applicata, 2011, 141(1): 45-51

31. Thom E R, Popay A J, Waugh C D, Minnee E M K. Impact of novel endophytes in perennial ryegrass on herbage production and insect pests from pastures under dairy cow grazing in northern New Zealand. Grass and Forage Science, 2014, 69(1): 191-204

32. Nan Z B, Li C J. Neotyphodium in native grasses in China and observations on endophyte/host interactions. In: Proceedings of 4th International Neotyphodium/Grass Interactions Symposium. Soest, Germany: University Paderborn, 2000, 41-50

33. Dapprich P, Paul V H, Krohn K. A novel and rapid staining method for the detection of vital endophytes in seeds and leaf sheaths of Lolium perenne. In: Krohn K, Paul V H, and Thomas J. (eds.). International Conference of Harmful and Beneficial Microorganisms in Grassland, Pastures and Turf. lOBC Bulletin, 1994, 17(1): 139-146

34. Beyer W F Jr, Fridovich I. Assaying for superoxide dismutase activity: some large consequences of minor changes in conditions. Analytical Biochemistry, 1987, 161(2): 559-566

35. Clairborne A. Catalase activity. In: Handbook of methods for oxygen radical research. Greenwald, R A. Boca Raton: CRC Press, 1985

36. Chance B, Maehly A C. Assay of catalases and peroxidases. Methods in Enzymology, 1955, 2: 764-775

37. Gupta A S, Webb R P, Holaday A S, Allen R D. Overexpression of superoxide dismutase protects plants from oxidative stress (induction of ascorbate peroxidase in superoxide dismutase-overexpressing plants). Plant Physiology, 1993, 103(4): 1067-1073

38. Bradford M M. A rapid and sensitive technique to determine protein concentrations. Analytical Biochemistry, 1976, 72: 248-254

39. Velikova V, Yordanov I, Edreva A. Oxidative stress and some antioxidant systems in acid rain-treated bean plants. Protective role of exogenous polyamines. Plant Science, 2000, 151(1): 59-66

40. Lichtenthaler H K, Wellburn A R. Determinations of total carotenoids and chlorophylls $\mathrm{b}$ of leaf extracts in different solvents. Biochemical Society Transactions, 1983, 11(5): 591-592

41. Dubois M, Gilles K A, Hamilton J K, Rebers P A, Smith F. Colorimetric method for determination of sugars and related substances. Analytical Chemistry, 1956, 28(3): 350-356

42. Tappel A L. Lipid peroxidation damage to cell components. Federation Proceedings, 1973, 32(8): 1870-1874

43. Zhang N, Raftery M, Richardson K, Christensen M J, Schmid J. Neotyphodium lolii induces a limited host defence response by Lolium perenne. In: Proceedings of the 6th International Symposium on Fungal Endophytes of Grasses. 2007, Dunedin, New Zealand: New Zealand Grasslands Association, 2007, 199-202

44. Morse L J, Day T A, Faeth S H. Effect of Neotyphodium endophyte infection on growth and leaf gas exchange of Arizona fescue under contrasting water availability. Environmental and Experimental Botany, 2002, 48(3): 257-268

45. Amalric C, Sallanon H, Monnet F, Hitmi A, Coudret A. Gas exchange and chlorophyll fluorescence in symbiotic and nonsymbiotic ryegrass under water stress. Photosynthetica, 1999, 37(1): 107-112

46. Monnet F, Vaillant N, Hitmi A, Coudret A, Sallanon H. Endophytic Neotyphodium lolii induced tolerance to $\mathrm{Zn}$ stress in Lolium perenne. Physiologia Plantarum, 2001, 113(4): 557-563

47. Rahman M H, Saiga S. Endophytic fungi (Neotyphodium coenophialum) affect the growth and mineral uptake, transport and efficiency ratios in tall fescue (Festuca arundinacea). Plant and Soil, 2005, 272(1-2): 163-171

48. Hunt M G, Rasmussen S, Newton P C D, Parsons A J, Newman J A. Near-term impacts of elevated $\mathrm{CO}_{2}$, nitrogen and fungal endophyteinfection on Lolium perenne L. growth, chemical composition and alkaloid production. Plant, Cell \& Environment, 2005, 28(11): 1345-1354

49. Storozhenko S, De Pauw P, Van Montagu M, Inzé D, Kushnir S. The heat-shock element is a functional component of the Arabidopsis APX1 gene promoter. Plant Physiology, 1998, 118 (3): 1005-1014

50. Moran J F, Becana M, Iturbe-Ormaetxe I, Frechilla S, Klucas R V, Aparicio-Tejo P. Drought induces oxidative stress in pea plants. Planta, 1994, 194(3): 346-352

51. Cheplick G P, Chui T. Effects of competitive stress on vegetative growth, storage, and regrowth after defoliation in Phleum pratense. Oikos, 2001, 95(2): 291-299

52. Pearson C P, Ison R L. Agronomy of Grassland Systems. Cambridg: Cambridge University Press, 1987

53. Hill N S, Stringer W C, Rottinghaus G E, Belesky D P, Parrott W A, Pope D D. Growth, morphological and chemical component responses of tall fescue to Acremonium coenophialum. Crop Science, 1990, 30(1): 239-255

54. Loewe A, Einig W, Shi L, Dizengremel P, Hampp R. Mycorrhiza formation and elevated $\mathrm{CO}_{2}$ both increase the capacity for sucrose synthesis in source leaves of spruce and aspen. New Phytologist, 2000, 145(3): 565-574

55. Latch G C M, Hunt W F, Musgrave D R. Endophytic fungi affect growth of perennial ryegrass. New Zealand Journal of Agricultural Research, 1985, 28(1): 165-168

56. Richardson M D, Chapman G W, Hoveland C S, Bacon C W. Sugar alcohols in endophyte-infected tall fescue under drought. Crop Science, 1992, 32(4): 1060-1061

57. White L M. Carbohydrate reserves of grasses: a review. Journal of Range Management, 1973, 26(1): 13-18

58. Karsten H D, Macadam J W. Effect of drought on growth, carbohydrates, and soil water use by perennial ryegrass, Tall fescue, and white clover. Crop Science, 2001, 41(1): 156-166

59. Hardy T N, Clay K, Hammondjr A M. Leaf age and related factors affecting endophyte mediated resistance to fall armyworm (Lepidoptera: Noctuidae) in tall fescue. Environmental Entomology, 1986, 15(5): 1083-1089

60. Hill N S, Pachon J G, Bacon C W. Acremonium coenophialummediated short- and long-term drought acclimation in tall fescue. 
Crop Science, 1996, 36(3): 665-672

61. Nan Z B. Incidence and distribution of endophytic fungi in seeds of some native and introduced grasses in China. Acta Prataculturae Sinica, 1996, 5(2): 1-8 (in Chinese)

62. Hoveland C S, Bouton J H, Durham R G. Fungal endophyte effects on production of legumes in association with tall fescue. Agronomy Journal, 1999, 91(6): 897-902

63. Rahman M H, Saiga S, Kodama Y, Tsuiki M. Effects of endophyte infection on tall fescue ecotypes grown in different andisols. Journal of Japanese Society of Grassland Science, 2017, 49: 406-407 